\title{
À la recherche du père perdu o un retorno a la diferencia
}

\author{
LILIANA WEINBERG \\ Universidad Nacional Autónoma de México
}

\section{Resumen}

Este artículo busca reexaminar la presencia del padre en la obra de Roland Barthes. En él se afirma que Louis Barthes, la borrosa figura paterna, brilla precisamente por su ausencia. La aparición de una nueva y monumental biografía de Roland Barthes preparada por Thiphaine Samoyault aporta nuevos elementos para recuperar datos hasta el momento perdidos en una caja de documentos procedentes de los archivos de Roland Barthes en los que quedan consignados algunos elementos autobiográficos. Estos elementos nos llevan a conjeturar que el padre muerto en el mar da lugar a una matriz interpretativa que caracterizamos como "retorno a la diferencia". Se esboza un breve recorrido por la obra de Barthes a partir de esta figura que puede ser leída también como una busca del padre perdido.

Palabras clave: Roland Barthes, biografía, figura del padre, discurso, escritura

\begin{abstract}
This paper attempts to reexamine the presence of the father in the work of Roland Barthes: Louis Barthes, the blurry paternal figure, is conspicuous precisely in his absence. The appearance of a new and monumental Roland Barthes biography by Thiphaine Samoyault brings to light autobiographical elements that until now had been lost in a box of documents in the Roland Barthes archives. These newly discovered facts give way to a new interpretative matrix brought on by the figure of the father who died at sea, and which I characterize as a "return to difference". The paper also makes a brief overview of Barthes's work taking as a starting point this father figure, which could also be read as the search for a missing or lost father.
\end{abstract}

Keywords: Roland Barthes, biography, father figure, discourse, writing 
Full fathom five thy father lies

Of his bones are coral made;

Those are pearls that were his eyes:

Nothing of him that doth fade

But doth suffer a sea-change

Into something rich and strange

-William Shakespeare, The Tempest

Cómo asomarse a la vida y al pensamiento de Roland Barthes a cien años de su nacimiento y cuando celebramos la aparición de una nueva y admirable biografía de Barthes, elaborada por Thiphaine Samoyault, que incorpora además de manera inédita nuevos datos de archivo, ficheros personales y agendas de nuestro autor? Si bien comencé esta tarea en cuanto studium - esto es, según lo dicho en Camera lucida, a partir del interés por reconstruir su biografía de acuerdo al devenir y los ciclos acostumbrados y apoyándome en un amplio número de fuentes-, acabé atraída por un punctum, esto es, un cierto elemento de la propia vida de Barthes que llegó de manera fuerte a mí, vino a buscarme, me atravesó. Se trata de un punto ciego: la presencia del padre. Si bien se ha dicho en muchas oportunidades que la figura de la madre, Henriette, es la de mayor peso en la vida de Barthes, y si según Philippe Sollers "la madre era su gran amor, el único", en lo que sigue quiero proponer que pensemos en Louis Barthes, la borrosa figura paterna que, sin embargo, brilla por su ausencia.

Al revisar la biografía de Roland Barthes, descubrimos que su padre, de origen gascón, tenía ya una larga trayectoria como marino cuando conoció a la alsaciana Henriette Binger durante un viaje en barco por el Océano Atlántico. Louis era alférez de navío cuando murió en un combate naval en el Mar del Norte el 27 de octubre de 1916, en el momento en que el patrullero Montaigne es alcanzado por cinco destructores alemanes en las cercanías del Cabo Gris Nez (Calvet 1992: 26-27). El padre muere entonces cuando el hijo, nacido el 12 de noviembre de 2015, no había cumplido aún el primer año de vida (Samoyault, 
2015). ${ }^{1}$ Sabemos también que fueron varios los años de precariedad en que vivieron en Bayona la viuda y el huérfano, desamparados por el Estado francés, que sólo en 1925 lo adoptará como "huérfano de guerra", tras un largo fallo judicial (Calvet 1992: 19-32). ${ }^{2}$

Como escribe Eduardo Berti en una excelente reseña de la obra de Samoyault, en el principio era el mar:

Al principio, está el mar. El mar donde sus padres, Louis y Henriette Barthes, se conocen viajando en un mismo barco. El mar de Cherburgo, la ciudad portuaria donde Roland nace el 15 de noviembre de 1915. El mar del norte donde el padre, Louis, muere en octubre de 1916, en plena guerra, a bordo de un viejo barco pesquero reconvertido en "patrullero". El mar de su abuelo materno, Louis-Gustave Binger, oficial de infantería de marina, héroe de los tiempos de conquista colonial, autor de libros que narran sus expediciones pioneras. $\mathrm{Y}$ el mar de Bayona y Biarritz, ciudades del sudoeste francés donde transcurre su infancia en semiorfandad un microcosmos fundamentalmente femenino, bastante digno de Proust, que incluye el descubrimiento de las ideas y las costumbres de la burguesía provincial. (Berti 2015)

La niñez de Roland Barthes transcurre así en un ambiente donde las voces, los discursos, los murmullos propios de la sociabilidad burguesa, individualista y provinciana se mezclan con la presencia indeterminada y el rumor permanente del mar.

Las primeras páginas del estudio de Samoyault evocan además las reflexiones del propio Barthes sobre la muerte como el único acontecimiento que resiste a la autobiografía, sobre el modo en que los seres humanos se acercan a la nada y responden discursivamente a ella, sobre el modo en que

1 Se trata de Roland Barthes; biographie, Paris, Seuil, 2015. Agradezco a mi amigo Adolfo Castañón que me haya permitido consultar este libro de rara circulación en nuestro medio.

2 Sigo aquí los datos aportados por la primera biografía completa de Barthes, que procede de Louis-Jean Calvet, Roland Barthes (1915-1980), Flammarion, 1990, en traducción al español de Alberto Luis Bixio, publicada en 1992 con el título Roland Barthes. Una biografía. 
la sociedad colma y elabora en torno a la nada, la nulidad, de ese momento límite: "se comprende la especie de acumulación salvaje que la sociedad elabora alrededor de la muerte: los anales, las crónicas, una Historia, todo aquello que puede nombrar y explicar, presentar un flanco al recuerdo y al sentido. Infierno muy generoso el del Dante - dirá Barthes en el tomo V de sus Obras completas (2002: 634-635) - donde los muertos son llamados por su nombre y comentados según sus faltas" (2015: 24). La muerte no sólo tiene necesidad de una crónica: ella demanda un relato. La muerte es el único evento que resiste a la autobiografía y justifica el gesto biográfico, puesto que será otro quien la tomará a su cargo y recuerda el interés que despertaba en Barthes "La verdad sobre el caso Valdemar", de Poe, cuyo personaje declara "Yo estoy muerto" y añade "Hay aquí un verdadero hápax de la gramática narrativa, puesta en escena de la palabra imposible en tanto que palabra: yo estoy muerto" (Barthes, 1993c: 344-345). Hay también en Barthes la fascinación por el Chateaubriand de la Vie de Rancé en cuanto representa el hacerse cargo por parte de otro, la tercera persona, del relato de la muerte. Un fragmento del Diario de Urt de 1977 lleva justamente por título "lo ficticio no muere". "La literatura - concluye Samoyault- está allí para protegernos de la muerte real... La muerte conduce a la escritura y ella justifica el relato de la vida" (2015: 26).

Perdidas en una caja de documentos biográficosy administrativos de los fondos de los archivos de Roland Barthes de la Biblioteca Nacional de Francia, siete hojas manuscritas, cortadas en dos y luego vueltas a pegar toscamente con cinta scotch, son la redacción tranquila de una tentativa autobiográfica, o los recuerdos todavía vivos de una memoria rota, de una 'memoria fragmentaria' como lo indica el subtítulo; podría tratarse [. . .] de una primera versión de las 'Anamneses' presentes en Roland Barthes por Roland Barthes, aunque también su forma antagónica o contraria, en cuanto se trata del único esfuerzo manifestado por el autor de un relato. (Samoyault 2015: 47)

1915: Je nais, dit-on, le 12 novembre a $9 \mathrm{~h}$ du matin, a Cherbourg, simple halte de garnison pour mon père, officier de la marine marchande mobilisé comme enseigne de vaisseau. 
1916: Mon père commande un chalutier (le Montaigne) en patrouille dans la Mer du Nord; le 28 octobre [sic], à hauteur du cap Gris-Nez, son bateau est coulé par les Allemands. (Barthes, 1975: 47)

En una ficha manuscrita, titulada "Mort de mon père" y fechada el 1 de agosto de 1979, reproduce Barthes los versos de La tempestad:

Ou furent ses yeux deux perles brillent.

Rien de lui ne s'est flétri dans le tombeau;

Tout en lui a ressenti la pouissance de la mer,

Et s'est revétu d'une substance précieuse et nouvelle.

(Samoyault, 2015: 76) ${ }^{3}$

He aquí el punctum: el padre caído en el agua se ha transformado en coral, perlas, brillantes; no queda de él un cuerpo que descanse en la tumba, sino que yace en el mar y ha resentido su potencia, que lo reviste de una sustancia preciosa y nueva. Desaparecida tan tempranamente la figura paterna, es posible conjeturar en la compleja trayectoria de pensamiento de Roland Barthes la búsqueda del padre perdido: un ejercicio que no implique apelar a la persecución del origen, puesto que nuestro autor, "obstinadamente antigenético" en verdad, descree de todo mito de origen, y está siempre alerta para denunciar las argucias de la doxa, que pretende reunir origen y verdad. La preocupación por traer a presente esa ausencia se evidenciará, por ejemplo, en su temprano interés por las etimologías, su fascinación por indagar las raíces de los términos, la curiosidad "que le hace buscar en las raíces de las palabras un fundamento del sentido" (Calvet, 1990: 33), pero que pronto lo llevará a inclinarse por la multiplicación analógica de los sentidos. La búsqueda imaginaria del lugar simbólico del padre se evidenciará en una apertura sin descanso posible, porque se pondrá siempre alerta ante cualquier espejismo del origen, siempre dispuesto a descubrir, una vez colocado provisionalmente en algún lugar simbólico, que allí no se detiene ni se sacia la

3 Esta traducción coincide con la de las Oeuvres dramatiques de Shak[e]speare, Traduits de l'anglais par Letourneur, Nouvelle édition précedé d’une notice biographique et littéraire par M. Horace Meyer, tome premier, Paris, Imprimerie de Amédée Saintin, éditeur, 1835. 
búsqueda, en cuanto todo acercamiento e intento de adopción de una certeza puede hacerlo caer en el peligro de desembocar en un modelo autoritario al que habrá a su vez que someter a crítica y del que habrá una vez más que migrar.

En este permanente interés por una búsqueda del sentido que acaba siendo un retorno a la diferencia, un retorno que no podrá ser nunca saciado por el héroe, ya que su camino crítico no conduce a lo uno del origen sino a la multiplicación, en una suerte de metonimia generalizada (Bensmaïa, 1986), de quien pronto se pondrá en guardia contra el peligro de la cristalización y la clausura del sentido, veo la cifra de la obra de Roland Barthes y en particular de su ensayo. Como ha escrito Grínor Rojo a propósito de la figura del padre en la obra de Gabriela Mistral (1997), no necesariamente las figuras materna y paterna aparecerán en la obra de un autor convertidas en personajes, sino que es posible rastrear su peso a través de las distintas formas y alcances de su ausencia o su presencia. Por otra parte, como recuerda el mismo crítico chileno, "padre y palabra se funden en Lacan": de allí el imperativo del verbo como la ley que da forma a una imagen. Lenguaje, deseo, mediación simbólica, don de la palabra, son componentes que se combinan y apuntan en última instancia a la figura paterna.

En un libro admirable dedicado al ensayo de Roland Barthes, Réda Bensmaïa (1986) ve que la clave, la figura mana, de toda la lectura que hace Barthes de la tradición ensayística y de su propia reconfiguración de la misma radica en un nuevo punto de partida, un nuevo eje: el cuerpo.

En así que propongo a través de estas páginas recuperar una nueva perspectiva para repensar la obra de Barthes: esta nunca saciada búsqueda del padre perdido. Se trata de un padre cuyo cuerpo ya no existe como tal, sino que yace transformado en sustancia de mar. Se trata de una búsqueda que siempre tiene en cuenta la posibilidad de tentarse por encontrar un sentido primero que, apenas atisbado, se verá siempre amenazado por incurrir en la cristalización y la clausura. Esa postergación es de algún modo la sublimación de la figura del padre. Veo en Barthes el permanente esfuerzo por ir en busca del sentido y el afán de nombrar aquello que por su propia exigencia se convierte en una búsqueda incansable, imposible de detener porque a su vez estará exigida por la voluntad de reabrir críticamente lo ya dicho, lo ya nombrado. 
La figura del padre se me aparece así para el caso de Barthes como una figura presente en su ausencia, que brilla por su ausencia, que permanece ya transformada en el mar (los huesos, corales; los ojos, perlas ...), clave de sentido postulada por quien se verá obligado a ir permanentemente en su busca: la búsqueda del otro que se ha inscrito en el texto, que dejó ahí su huella, múltiple.

La búsqueda de la figura paterna, "de la restitución de lo abolido", de la representación en presencia de una ausencia, que en otros casos - como en la novela de Proust- precede a la existencia del niño, manda desde afuera, decide sobre su destino al punto de autorizar o negar los momentos de placer. (El padre es en la novela de Proust quien decide arbitraria y autoritariamente, si hoy habrá o no beso de la madre al niño que tiene miedo a la oscuridad). No es tampoco el padre autoritario que, como en el caso de Kafka y Benjamin, se erige como el modelo mismo del orden burgués, capaz de marcar a fuego el destino del hijo. Ni es tampoco, en el otro extremo, el padre de Picasso, pintor derrotado por el genio del hijo (como es el caso del análisis que le dedica John Berger), quien queda así abandonado al propio capricho, a la propia potencia creativa, a la libertad sin límites.

Entre estos modelos posibles de la figuración del padre podemos ubicar el caso de Barthes, un caso diferente y particular, ya que se trata del hijo huérfano que va en busca de esa presencia ausente, ese lugar simbólico donde padre y palabra se funden, va en busca de un principio de organización oculto en las cosas, un principio de orden universal pero no autoritario ni primero, ya diferente, ya diferido, que invita a un retorno a la diferencia, una búsqueda obstinadamente desenmascaradora de la voluntad de principio por el que la doxa confunde origen y verdad, al que irá poniendo distintos nombres a lo largo de su vida, para de inmediato someterlos a la prueba del lenguaje y a la crítica antiautoritaria.

Así, por ejemplo, su tan comentada afirmación de "la muerte del autor" es a la vez el reconocimiento de una ausencia, la crítica del autor como principio del sentido del texto y la advertencia del peligro de que la afirmación autoritaria del autor nos haga caer en la trampa de un principio único de sentido, para a la vez celebrar la apertura a innúmeras potencialidades de lectura que sean 
búsquedas activas del poder del texto a la vez que estrategias capaces de sortear los peligros del texto del poder.

No me propongo emprender aquí una lectura psicoanalítica, sino sugerir, de manera más cercana a las operaciones de la imaginación simbólica (en la línea de Durand o Bachelard), un principio operativo, simbolizador y configurativo que acompaña la mirada de Barthes: partir en busca de un orden perdido, ausente o nunca encontrado, para llegar al cual se debe desmontar toda ilusión genealógica y sortear el peligro del falso orden que ofrece el poder - sea éste representado por el Estado, la jerarquía académica o el sistema autoritario¿será posible alcanzar por fin un orden garante del sentido, o el precio de encontrarlo será siempre el sacrificio de la libertad y el disenso?

Lo cierto es que, en su compleja relación con la cultura europea de posguerra, veo a Barthes como un gran viajero lúcido obligado a recorrer sin una guía previa el exasperado siglo XX que exigía permanentemente a Francia llevar la delantera en la formulación de nuevas preguntas y nuevas respuestas. Las posibles guías, explicaciones y principios de orden se abrazan pero pronto, desvelado su secreto impulso autoritario, se someten a crítica y se desenmascaran como cierres de la libertad del sentido.

La obra de Barthes, sensible como pocos a los acelerados cambios que se dieron en la política, la cultura y la sociedad, pero también en la ciudad letrada y en la correlación de fuerzas de la vida académica, habrá de atravesar distintas estaciones en un recorrido que, conjeturo, pudo estar guiado por la búsqueda de un padre capaz de dar sentido al mundo de una manera generosa y abierta, sin clausuras autoritarias. Un camino amoroso pero arduo. ¿Será por eso que alguna vez consideró que "El discurso amoroso es hoy de una extrema soledad"?

Nacido en 1915, esto es, en plena Primera Guerra mundial, en plena caída de un orden, de una época y de un mundo, para formarse en los años críticos de entreguerra y convertirse muy pronto en testigo de las miserias de la segunda guerra mundial, sus primeros años de producción crítica estarán teñidos de una fuerte militancia periodística y una voluntad de intervención en los debates de la hora, con particular atención en las propuestas existencialistas y la sacudida crítica de los valores de la burguesía. 
Es posible que Barthes encontrara en Sartre uno de sus primeros maîtres à penser: el filósofo que somete a crítica la institución literaria y que, al mismo tiempo que se pregunta qué es la literatura, se preocupa también por la relación entre el hombre, la historia, la circunstancia. En esa interrelación entre historia y libertad, en esa toma de conciencia de la relación entre práctica literaria y praxis social, el joven Barthes se ve precisado a preguntarse respecto del lugar de la actividad escrituraria, que para Sartre se muestra ya como tensión entre la libertad que demanda la literatura en cuanto actividad autónoma y las exigencias de dar cuenta de su compromiso con el mundo y con la historia. Sartre abre así a una tensión que Barthes habrá de responder en El grado cero de la escritura (1953), donde abordará la escritura como una manifestación en sí misma de la estructura determinada y determinante del lenguaje. Esta tensión irresuelta abrirá a Barthes a ese otro padre por excelencia, de alcance omnipresente aunque no omnipotente: el lenguaje, y será además cifra de su fascinación por un lenguaje que ve como "abierto, infinito, libre de cualquier ilusión referencial". Recordemos que el propio Barthes, en La aventura semiológica, habló de la primera etapa de su obra como la del deslumbramiento ante el lenguaje: un deslumbramiento que aparece en El grado cero de la escritura, donde esta operación se abre sitio en el espacio de lo dado por el lenguaje.

El lenguaje define un espacio de posibilidad, dado no tanto por su carácter instrumental y por sus límites sino precisamente por una apertura: el "horizonte de inteligibilidad". La escritura es una operación que se hace posible en el espacio abierto por las potencialidades del lenguaje, al que a su vez la historia y la tradición dotan de una cierta determinación, mientras que el estilo manifiesta los caracteres biográficos y personales. El lenguaje es una estructura material de significados históricamente determinados pero también históricamente determinantes, y de allí que el estilo se convierta para Barthes en el encuentro entre lo personal y lo institucional, en el que se evidencia un primer atisbo de la emancipación del significante respecto de un significado concebido como determinado y determinante. Es dentro de este espacio de elementos ya dados que, según Barthes, el escritor escoge un modo de escritura, una forma. Y una vez más, esta forma no debe entenderse sólo como un objeto o cosa predeterminado. La forma no carece de significación, sino que es en sí misma 
un sistema de signos que trae aparejado un cierto significado sociohistórico. Este segundo orden de significación dado por la propia forma provee al autor de unas condiciones objetivas, de una zona de significado ya dado, preexistente, que al mismo tiempo define y constriñe la posibilidad de ser escritor: es el lugar donde alguien se convierte en escritor a partir de la elección de cómo convertirse en tal. La forma es el lugar donde el escritor se encuentra "comprometido" ("il est engagé"), o más bien, en el caso de Barthes, donde el escritor se compromete. Y esta ambigüedad abierta por la forma reside en el corazón mismo de las distintas maneras de escribir.

Tal vez el primer asomo de un arrobamiento ante la figura omniabarcadora aunque no autoritaria del padre es la que Barthes descubre en el lenguaje y su sistema. El lenguaje es nuestra casa, a través de su profundo carácter social (el lenguaje es, para Tomás Segovia, la institución social por excelencia), nos cobija y cobija también la posibilidad de estudiarlo, conocerlo y aprender de él. De allí la fascinación ante el modelo saussuriano, que descubre las grandes claves de esta sinfonía infinita: la posibilidad de descubrir una relación arbitraria entre significante y significado, esto es, descubrir el carácter culturalmente marcado de toda convención, pero al mismo tiempo la posibilidad de fundar una actividad estructural, modelizadora, que indague los sentidos y entregue herramientas de comprensión del mismo. Hacer un análisis estructural del relato y proponer un sistema de los signos es extender al mundo literario y cultural un análisis objetivo capaz de descubrir y desmontar los mecanismos secretos de un modelo autoritario que impone como naturalizado lo que es en realidad fruto de una imposición hegemónica. Al mismo tiempo que nos tienta buscar en el lenguaje el modelo de una existencia objetiva, preexistente y previa a los avatares de la historia, pronto será necesario regresar a él para atender tanto a los procesos de significación como las posibilidades de formalización y constitución de sistema.

Es así como en la etapa de los años cincuenta Barthes sienta las bases del análisis de la condición histórica del lenguaje literario y delimita los conceptos de lengua, estilo y escritura: El grado cero de la escritura (Le degré zéro de l'écriture, 1953), Michelet por él mismo (Michelet par lui même, 1954), Mitologías (Mytologies, 1957), le darán las herramientas para hacer una disección de "esa especie de monstruo que es la pequeña burguesía", con sus abusos ideológicos. 
Entramos en la década de los años sesenta y nos acercamos al 68. Es entonces cuando descubrimos, en retrospectiva, que mucho de lo hecho previamente por el propio Barthes, y su propia polémica con Picard en que defiende nuevos caminos críticos contra la mirada académica, lo convertirá en uno de los más lúcidos antecedentes del 68, aun cuando los estudiantes de la contestation determinen que "las estructuras no salen a la calle". En efecto, ya en 1964 se habían publicado sus Ensayos críticos, en los que tomaba en consideración los puntos sobresalientes de la temática literaria más viva en Francia, afrontando de lleno, en una confrontación crítica con el estructuralismo, la problemática del significado de la obra literaria. Los esfuerzos de Barthes también se encaminaron a sentar, de manera crítica, las bases de una teoría de los signos, es decir, de una "semiología", intentando situar la ciencia de los signos —en el sentido más lato del término- dentro del campo de la lingüística: Elementos de semiología (Éléments de sémiologie, 1964), Sistema de la moda (Le système de la mode, 1967).

La polémica con Raymond Picard marca también un hito en la vida de un hombre que busca un deslinde del padre autoritario, que busca la desmitificación de la institución literaria, que repiensa el lugar de la academia respecto de la vida: ante la eclosión de nuevos procesos urbanos y escriturales, ante la pinta en la calle, el artículo polémico, el debate de ideas, las nuevas manifestaciones literarias, ¿es posible seguir aplicando viejos esquemas críticos? ¿O será más oportuno abrir las puertas de la universidad a la vida y esbozar nuevas formas de la crítica que acompañen a las nuevas escrituras?

Es así como en Crítica y verdad (Critique et vérité, 1966) defendió las razones de la "nueva crítica" frente al modelo académico tradicionalista representado por Picard, y de algún modo la polémica sobre qué hacer con Racine. En la reunión de distintos escritos críticos sobre Racine, Barthes dirá (apelando a este motivo que creo ir encontrando): “... la literatura es en esencia, como creo que lo es, al mismo tiempo sentido planteado y sentido frustrado". Y de inmediato:

Escribir es estremecer el sentido del mundo y plantear una pregunta indirecta que el escritor, por medio de una última incertidumbre, se abstiene 
de responder. La respuesta la dará cada uno de nosotros, aportándole su historia, su lenguaje, su libertad; pero como historia, lenguaje y libertad cambian sin cesar, la respuesta que da el mundo al escritor e infinita: nunca se acaba de responder aquello que ya fue escrito fuera de toda respuesta: primero afirmados, después enfrentados, más tarde remplazados, los sentidos pasan, la pregunta persiste. (1963: 45)

Ya en los años setenta, en la colección "Tel Quel”, publicó un nuevo volumen crítico, $S / Z$, en el que analizaba sutilmente el Sarrasine de Balzac. Revisemos, a la luz de nuestra propuesta, el comienzo de esta obra, donde se plantea la hermética diferencia entre lo escribible y lo legible:

Se dice que a fuerza de ascesis algunos budistas alcanzan a ver un paisaje completo en un haba. Es lo que hubiesen deseado los primeros analistas del relato: ver todos los relatos del mundo ... en una sola estructura: vamos a extraer de cada cuento un modelo, pensaban ... tarea agotadora y finalmente indeseable, pues en ella el texto pierde su diferencia ... Esta diferencia no es evidentemente una cualidad plena, irreductible, no es lo que designa la individualidad de cada texto, lo que lo nombra, lo señala, lo termina, por el contrario, es una diferencia que no se detiene y se articula con el infinito de los textos, de los lenguajes, de los sistemas: una diferencia de la que cada texto es el retorno.

Nuestra evaluación sólo puede estar ligada a una práctica, y esta práctica es la de la escritura. De un lado está lo que se puede escribir, y del otro, lo que ya no es posible escribir: lo que está en la práctica del escritor y lo que ha desaparecido de ella: ¿qué textos aceptaría yo escribir (re-escribir), desear, proponer, como una fuerza en este mundo mío? Lo que la evaluación encuentra es precisamente este valor: lo que hoy puede ser escrito (re-escrito): lo escribible. ¿Por qué es lo escribible nuestro valor? Porque lo que está en juego en el trabajo literario (en la literatura como trabajo) es hacer del lector no ya un consumidor, sino un productor del texto $[\mathrm{Y}]$ frente al texto escribible se establece su contravalor, su valor negativo, reactivo: lo que puede ser leído pero no escrito: lo legible (1980a: 1 , el subrayado es mío). 
En El placer del texto (1973) la pregunta acerca de cuál es el placer de la lectura y la consiguiente respuesta - en la que se observa que dicho placer tiene la peculiaridad de no poder enunciarse ni explicitarse- se plantean como problemas fundamentales frente a una concepción que reduce la literatura y los textos literarios a pura retórica, considerándolos meros ornamentos.

Y será a partir de 1975 - fecha de publicación de un texto breve titulado Roland Barthes por Roland Barthes, libro de introducción a su obra- que nuestro autor adoptará una actitud crítica frente a las posiciones más combativas de los comienzos de su carrera o de las propias posiciones "cientificistas" de su etapa semiótica, para perfilar de manera más radical el problema de la subjetividad, del placer y del deseo en el texto. Así, por ejemplo, hará del grano de la voz "un mixto erótico del timbre y del lenguaje, la paradoja de una escritura sonora" (1993a: 108). Extraigo de este libro otro ejemplo del modo operativo de Barthes, quien al hablar de "Doxa/paradoxa", dice:

Formaciones reactivas: una doxa (una opinión común) está establecida, insoportable; para desprenderme de ella postulo una paradoja; luego esa paradoja se espesa, se convierte, a su vez, en una nueva concreción, una nueva doxa, y tengo que ir más lejos en busca de una nueva paradoja.

Hagamos de nuevo este recorrido. En el origen de la obra, la opacidad de las relaciones sociales, la falsa Naturaleza; la primera sacudida es pues la desmistificación (Mythologies); luego la desmistificación se inmoviliza en una repetición y es a ella a quien hay que desplazar: la ciencia semiológica (postulada entonces) intenta quebrantar, vivificar, armar el gesto, la postura mitológica, dándole un método; esta ciencia se recarga a su vez de todo un imaginario: a las aspiraciones de una ciencia semiológica se impone la ciencia (a menudo bastante triste) de los semiólogos; hay pues que apartarse de ella, que introducir, en ese imaginario razonable, un grano de deseo, la reivindicación del cuerpo: es entonces el Texto, la teoría del Texto. Pero de nuevo el Texto corre el peligro de petrificarse: se repite, se almoneda en textos mates que testimonian una solicitación de lectura y no un deseo de agradar: el Texto tiende a degenerar en Parloteo. ¿A dónde ir? En eso estoy. (1978: 78-79) 
Una respuesta posible es la que dio a propósito de Cobra de Severo Sarduy, cuando exclama "encore, encre, encore plus!": de nuevo, de nuevo, un poco más... encore un autre mot, encore une autre fête: aún otra palabra, aún otra fiesta" (1993a: 17-18).

En 1977 publica Fragmentos de un discurso amoroso, ensayo-novela en el que, a través de fragmentos, alusiones y citas, Barthes reflexiona sobre la "soledad extrema" de un discurso imposible (tan imposible como la propia relación amorosa, en la que el amado, el otro, siempre resulta escurridizo e inalcanzable) que, al ser pronunciado por todos, es excluido, burlado y apartado por los discursos cercanos y desdeñado por las ideologías. Allí aparece una y otra vez, de la "a" a la "zeta", el principio a que ya he aludido: "Abismarse: ataque de anonadamiento que se apodera del sujeto amoroso, por desesperación o plenitud... La explosión de abismo puede venir de una herida pero también de una fusión" (1993b: 30). Y más adelante:

'Verdad: todo episodio de lenguaje llevado a la 'sensación de verdad' que el sujeto amoroso experimenta pensando en su amor... El otro es mi bien y mi saber: yo sólo lo conozco, lo hago existir en su verdad. Cualquiera que no sea yo lo desconoce... Inversamente, el otro me funda en verdad: no es sino con el otro que me siento yo mismo" (1993b: 325).

Los años ochenta son los de sus últimas obras, como Cámara lúcida (La chambre claire, 1980), obra en que la muerte de la madre detona reflexiones sobre el tiempo y el registro de lo fotografiable. Escribe allí, por ejemplo, que "La Historia es histérica. Sólo se constituye si se la mira, y para mirarla es necesario estar excluido de ella" (1990: 118). Con esta observación retorno a mi punto de partida y cierro con un pasaje del discurso amoroso:

No puedo pues darte lo que he creído escribir para ti; a ello debo rendirme... La operación en que se apresa al otro no es un encabezado. Es, más profundamente, una inscripción: el otro está inscrito, se ha inscrito en el texto, dejó ahí su huella, múltiple. Si, de ese libro, tú no fueras más que quien lo dedica, no saldrías de tu dura condición de objeto amado, de dios; pero tu presencia en el texto, por lo mismo que eres allí irreconocible, no 
es la de una figura analógica, la de un fetiche: es la de una fuerza que o está, desde ese momento, segura. Poco importa, pues, que te sientas continuamente reducido al silencio, que tu propio discurso te parezca ahogado bajo el discurso, monstruoso, del objeto amoroso... el otro no habla, pero inscribe algo en cada uno de los que lo desean...; es verdad que ese mudo es un ángel (1993b: 118-119).

\section{Referencias bibliográficas}

BARThes, Roland (1971 [1966]): Crítica y verdad, trad. de José Bianco, México: Siglo XXI.

BARTHES, Roland (1978 [1975]), Roland Barthes par Roland Barthes, trad. de Julieta Sucre, Barcelona: Editorial Kairós.

Barthes, Roland (1980a [1970]): S/Z, trad. de Nicolás Rosa, México: Siglo XXI.

Barthes, Roland (1980b [1971]): Sade, Fourier, Loyola, París: Éditions du Seuil.

Barthes, Roland (1981 [1964]): Essais critiques, París: Éditions du Seuil.

BARTHES, Roland (1990 [1980]): La cámara lúcida. Nota sobre la fotografía, trad. de Joaquim Sala-Sanahuja, Buenos Aires: Paidós.

Barthes, Roland (1992 [1963]): Sobre Racine, trad. de Jaime Moreno Villarreal, México, Siglo XXI.

BARTHES, Roland (1993a [1973]): El placer del texto y lección inaugural, trad. de Nicolás Rosa y Óscar Terán, Madrid - México: Siglo XXI.

BARTHEs, Roland (1993b [1977]): Fragmentos de un discurso amoroso, trad. de Eduardo Molina, Madrid - México, Siglo XXI.

BARTHES, Roland (1993c [1985]): La aventura semiológica, trad. de Ramón Alcalde, Barcelona: Paidós. 
BARTHEs, Roland (1997 [1953]): El grado cero de la escritura. Nuevos ensayos críticos, trad. de Nicolás Rosa. México-Madrid: Siglo XXI.

Barthes, Roland (2002): Euvres Complètes, t. 5, Livres, textes, entretiens 1977-1980, París: Éditions du Seuil.

BensmaïA, Réda (1986): Barthes à l'Essai. Introduction au texte réfléchissant, Tübingen: Gunter Narr Verlag.

Berger, John (1965): The Success and Failure of Picasso. New York: Vintage International.

BERTI, Eduardo (2015): «Una revolución llamada Roland Barthes», en La Nación, Buenos Aires, 15 de mayo de 2015 (http://www.lanacion.com. ar/1792811-una-revolucion-llamada-roland-barthes).

CAlvet, Louis-Jean (1990): Roland Barthes (1915-1980), París: Flammarion.

Calvet, Louis-Jean (1992): Roland Barthes. Una biografía, trad. de Alberto Luis Bixio, Barcelona: Gedisa.

Rojo, Grínor (1997): Dirán que está en la gloria, Santiago de Chile, FCE.

Samoyault, Thiphaine (2015): Roland Barthes; biographie, Paris, Seuil. 